\title{
Polymeric Electrospinning for Musculoskeletal Regenerative Engineering
}

\author{
Naagarajan Narayanan ${ }^{1,2}$ • Chunhui Jiang ${ }^{1,2}$ • Gozde Uzunalli ${ }^{1,2}$. \\ Shalumon Kottappally Thankappan ${ }^{3,4}$ - Cato T. Laurencin ${ }^{3,4,5,6,7,8} \cdot$ Meng Deng $^{1,2,9,10}$
}

Received: 30 October 2015 / Accepted: 3 March 2016 /Published online: 30 March 2016

(C) The Regenerative Engineering Society 2016

\begin{abstract}
Musculoskeletal tissue loss or damage resulting from trauma, surgery, or disease presents a significant medical challenge. Current therapies involving grafts are hindered by concerns over donor site morbidity and limited functional improvement. Regenerative engineering emerges as a promising transdisciplinary strategy for tissue repair and regeneration based on the convergence of tissue engineering, advanced materials science, stem cell science, and developmental biology. Of particular interest is the development of cell-instructive matrices that closely mimic the properties of the native tissues. Electrospinning provides a versatile technology platform for the design and fabrication of nanofiber-based scaffolds that are similar to natural extracellular matrix. Biodegradable polymers constitute an attractive class of biomaterials for the development of electrospun structures due to flexibility in chemistry and the ability to be excreted or resorbed by the body. Here, we highlight the importance of material cues on cellular responses and discuss recent advances in the development of electrospun polymeric structures as biomimetic matrices to
\end{abstract}

Meng Deng

deng65@purdue.edu

1 Department of Agricultural and Biological Engineering, Purdue University, West Lafayette, IN 47907, USA

2 Bindley Bioscience Center, Purdue University, West Lafayette, IN 47907, USA

3 Institute for Regenerative Engineering, University of Connecticut Health Center, Farmington, CT 06030, USA

4 Raymond and Beverly Sackler Center for Biomedical, Biological, Physical and Engineering Sciences, University of Connecticut Health Center, Farmington, CT 06030, USA regenerate musculoskeletal tissues with a focus on the work involving bone, tendon, skeletal muscle, and their interfaces.

\section{Lay Summary}

Scaffold-based regenerative engineering represents a clinical translational strategy for tissue regeneration. A scaffold offers an engineered cell microenvironment to direct cell migration, growth, differentiation, and organization to form regenerated tissue. Successful tissue regeneration critically depends on the development of scaffolds that mimic the hierarchical architecture of native tissue extracellular matrix. In particular, electrospun polymer nanofibers provide an enabling technology platform to engineer a scaffold system with an appropriate combination of physical, chemical, and biological properties for regeneration of various musculoskeletal tissues.

Keywords Polymers · Regenerative Engineering · Electrospinning $\cdot$ Musculoskeletal tissues
5 Department of Orthopaedic Surgery, University of Connecticut Health Center, Farmington, CT 06030, USA

6 Department of Chemical and Biomolecular Engineering, University of Connecticut, Storrs, CT 06269, USA

7 Department of Materials Science and Engineering, University of Connecticut, Storrs, CT 06269, USA

8 Department of Biomedical Engineering, University of Connecticut, Storrs, CT 06269, USA

9 School of Materials Engineering, Purdue University, West Lafayette, IN 47907, USA

10 Weldon School of Biomedical Engineering, Purdue University, West Lafayette, IN 47907, USA 


\section{Introduction}

Musculoskeletal tissue loss or damage resulting from trauma, surgery, or disease presents a significant challenge in health care [1]. Current treatment options involving autografts and allografts are hindered by the limited availability and risks of immunogenicity, respectively. In order to develop functional tissue substitutes, a transdisciplinary regenerative engineering strategy has emerged based on the convergence of tissue engineering, advanced materials science, stem cell science, and developmental biology $[2,3]$. In a classical scaffold-based regeneration process, scaffolds provide a three-dimensional (3D) inductive environment to direct cell behavior and guide tissue morphogenesis and development [1]. Degradable polymers are attractive candidate scaffold materials due to the ability to be excreted or resorbed by the body and versatility in chemistry for material optimization $[4,5]$. Ideally, the scaffolds should exhibit excellent biocompatibility and degrade with a degradation rate that matches the rate of natural healing process. The scaffolds should be able to support physiological loading and match the mechanical properties of the replaced tissues. Table 1 summarizes the mechanical benchmark values for several representative musculoskeletal tissues. It can be noted that the mechanical properties of the tissues vary dramatically with respect to their tissue location, structure, and function. Furthermore, scaffolds should provide appropriate architectures and material cues to facilitate cell-material interactions. The interaction of cells with materials has proven to be a robust signaling modality in controlling cellular processes $[2,3]$. Incorporation of tissue-inducing factors enhances the biological performance of these scaffolds in tissue repair and regeneration. Several commonly used fabrication methods of producing tissue-engineered scaffolds include solvent casting and particulate leaching, phase separation and freeze drying, solution spinning, microsphere sintering, and rapid prototyping technologies [12].

Collective advances in the areas of materials science and micro/nanoscale engineering have provided a robust toolbox for rational design of a variety of complex structures that exhibit appropriate combination of physical, chemical, and biological properties for regeneration of functional tissues. For example, biodegradable polyphosphazenes comprising an inorganic backbone of alternating phosphorous and nitrogen atoms constitute a unique class of biomaterials offering flexibility to fine-tune polymer properties by modulating side group chemistry [13]. On the other hand, advancements in nanotechnology have made it possible to investigate different material cues on the complex cellular processes at the nanoscale and fabricate structures mimicking those of the natural tissues $[1,14]$.

Polymeric nanofibers due to their similarity to natural extracellular matrix (ECM) have been actively investigated for musculoskeletal tissue regeneration $[1,15]$. A typical polymeric nanofiber scaffold is composed of ultrathin continuous fibers with high surface-to-volume ratio and porosity. Electrospinning provides a versatile technology platform for the design and fabrication of nanofiber-based matrices from various biodegradable polymers due to the ease of fabrication, efficient control over the process, and easy scale-up [16]. In 1934, the first patent on the process of developing polymeric nanofibers via electrospinning was reported by Anton Formhals [17]. In the electrospinning process, polymeric nanofibers are created from a jet of polymer solution under the influence of applied electrical field between an ejecting needle and a collector (Fig. 1) [1, 17]. Fibers with diameters ranging from few nanometers to several micrometers can be obtained via electrospinning process. Several critical parameters that control the process include the following: polymer solution viscosity and flow rate, applied electrical potential, distance between spinneret and collector, motion of the grounded target, and ambient conditions. In addition, the structure of the fabricated fibers can be controlled by altering the type of collector. For example, aligned fibers can be obtained by using a rotating collector, whereas random fibers can be obtained with a flat plate collector (Fig. 1). Laurencin and colleagues demonstrated for the first time the potential of electrospun scaffolds from poly(lactide-co-glycolide) (PLGA) for applications in engineering tissues [18]. This

Table 1 Mechanical benchmark values for different musculoskeletal tissues

\begin{tabular}{llll}
\hline Type of tissues & Testing methods & Modulus & References \\
\hline Human cortical bone & Tensile testing & $14-20 \mathrm{GPa}$ & {$[6]$} \\
Human trabecular bone & Compression testing & $0.02-0.9 \mathrm{GPa}$ & {$[7]$} \\
Human Achilles tendon & Tensile testing & $598-1034 \mathrm{MPa}$ & {$[8]$} \\
Mouse extensor digitorum longus (EDL) muscle & Atomic force microscopy indentation & $10-20 \mathrm{kPa}$ & $350-475 \mathrm{kPa}$ \\
Rabbit EDL muscle & Tensile testing & $5.5-11.8 \mathrm{MPa}$ & {$[10]$} \\
Human articular cartilage (knee) & Compression testing & {$[11]$} & \\
\hline
\end{tabular}

It can be noted that the mechanical properties of the tissues vary dramatically with respect to their tissue location, structure, and function 


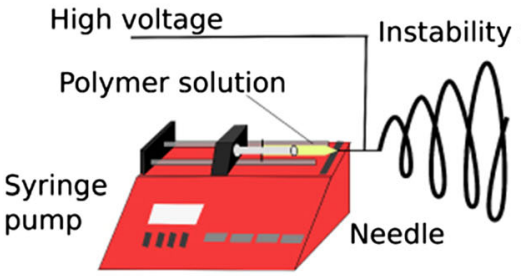

Fig. 1 Schematic illustration of a general electrospinning setup consisting of a high voltage power supply, a syringe with a needle, a syringe pump, and a conductive collector. A high electric potential is applied between the needle and the collector inducing formation of a polymer jet as the repulsive electrostatic force overcomes the surface tension of the polymer solution. The polymer jet undergoes a series of

pioneering work has been highlighted as one of the top 25 papers published by the Journal of Biomedical Materials Research over the past 50 years. As presented in Fig. 2, a recent literature survey based on a SciFinder Scholar search for electrospinning and polymers clearly demonstrates the growing interest during the past decade. So far, polymeric materials have been fabricated by electrospinning into various nanofiber structures such as random nanofibers [18, 19], aligned nanofibers [20,21], polymer/ceramic nanocomposites $[22,23]$, micro/nanofiber composites [24, 25], core-shell nanofibers [26, 27], and 3D structures [28-30]. Both natural and synthetic polymers have been extensively researched in the development of tissue engineering scaffolds $[4,5]$. Some of the widely investigated polymers include collagen [31], chitosan [32, 33], cellulose [34], poly(lactic acid) (PLA) [35], poly(glycolic acid) (PGA) [36], poly(عcaprolactone) (PCL) [37], PLGA [18, 38, 39], and polyphosphazenes [28, 40-42].

In this article, we highlight the importance of different material cues governing the cell-material interactions at the nanoscale, thereby providing fundamental insights into rational design of regenerative engineering scaffolds. We further discuss recent advances in the development of electrospun polymeric structures to regenerate musculoskeletal tissues with a focus on the work involving bone, tendon, skeletal muscle, and their interfaces.

\section{Cell-Material Interactions at the Nanoscale}

Cells residing within their natural ECM experience interplay with cell-cell communication and cell-matrix
Flat plate Random fibers

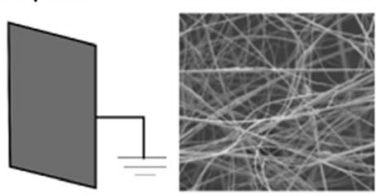

Rotating drum Aligned fibers
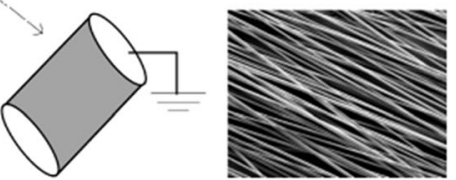

electrically driven bending and stretching instabilities that result in formation of thin fibers. The organization and structure of the fibers can be controlled by varying the type of collector and its motion. a Stationary flat plate collectors generate random fibers. Rotating targets such as b rotating drum collectors result in aligned fibers

interactions. These interactions are regulated by their complex microenvironment involving various cellinstructive cues from ECM [1, 14]. For example, stem
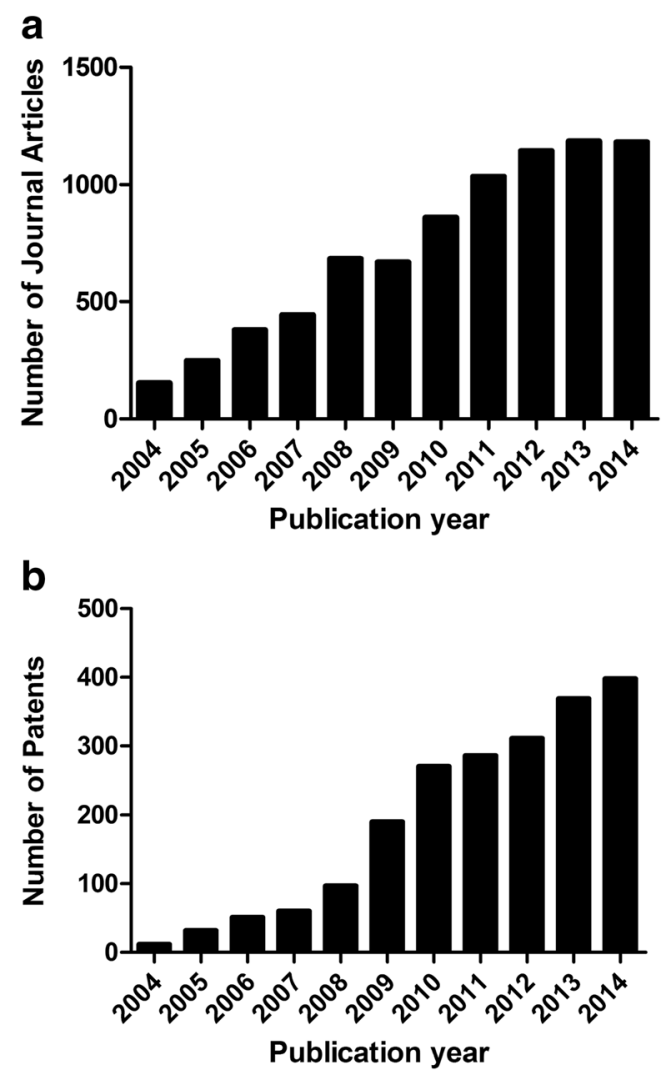

Fig. 2 A SciFinder Scholar research survey conducted using the research topic "electrospinning and polymers" illustrates a steady increase in the a number of journal articles and $\mathbf{b}$ number of total patents over the past decade 
cell microenvironment (niche) exerts effects on driving distinct lineage differentiation and maintaining selfrenewal [43-46]. The ECM is composed of hierarchically arranged collagen, laminin, other fibrils, and proteoglycans presenting a complex milieu in the nanometer scale. Biomaterials are designed to recapitulate natural ECM and the cell-material interactions are influenced by material characteristics [47-50]. In general, the first phase of cell-material interactions involves protein adsorption, which occurs on contact with body fluids and is influenced by the physicochemical characteristics of the material and its fabricated form. This is followed by the cell adhesion phase involving various biological molecules such as ECM, cell membrane, and cytoskeletal protein components. These interactions modulate cellular responses in terms of cell migration, proliferation, and differentiation. Of particular interest in a regenerative engineering strategy is to understand effects of various material cues on cell-material interactions at the nanoscale and develop advanced scaffolds that are capable of guiding cell function and inducing tissue regeneration. The material properties in controlling the cell-material interactions can be broadly classified as physical, chemical, and biological cues (Fig. 3). Integrating these cues is especially critical in engineering complex tissues that have multiple cell types and require precisely defined cell-cell and cellmatrix interactions in a $3 \mathrm{D}$ environment.

\section{Physical Cues}

Physical cues involve the physical interactions between cells and materials. Material physical cues such as topography, stiffness, and porosity have profound effects on cell function and tissue development. For example, materials with different nanotopography such as nanofibers, nanopillars, nanochannels, nanopits, or nanopillows have been investigated for regulating cell fate and differentiation [51, 52]. Human embryonic stem cells (hESCs) cultured on nanopillars ( $30 \mathrm{~nm}$ in diameter hexagonal or honeycomb nanotopography) could maintain expression of Oct4, a pluripotent gene, without supplementation of basic fibroblast growth factor (bFGF) [53]. With bFGF supplementation, Oct 4 expression of hESCs was maintained on the hexagonal nanotopography but showed a downregulation on the honeycomb configuration. It has also been shown that mesenchymal stem cells (MSCs) seeded on nanopits show enhanced osteogenic differentiation without any osteogenic differentiation supplements [54]. Nanotopographical cues such as alignment are crucial for regeneration of muscle tissues. In the organism, skeletal muscle fibers are aligned in bundles enabling an anisotropic organization. Aligned polymeric fibers fabricated via electrospinning of PLGA (85:15) generated contact guidance for myoblast elongation and alignment [55]. Aligned nanofibrous scaffolds facilitated cell alignment and proliferation as well as myotube assembly [56]. Matrix stiffness plays an important role in regulating cell function and cell fate [57-59]. Cells in different tissues are tuned to the specific
Fig. 3 Design criteria for different material cues on cellmaterial interactions at the nanoscale. Physical cues, such as material topography, stiffness, and porosity, can dramatically affect cell fate and tissue development. Incorporation of chemical cues in the form of simple chemical groups into materials influences cell behavior. Additionally, material carrier presentation of various biological cues such as growth factors and small molecules/inducerons can lead to enhanced cellular responses. Integrating these cues is paramount in creating a synthetic matrix optimized for desirable cellular responses and inductive tissue regeneration

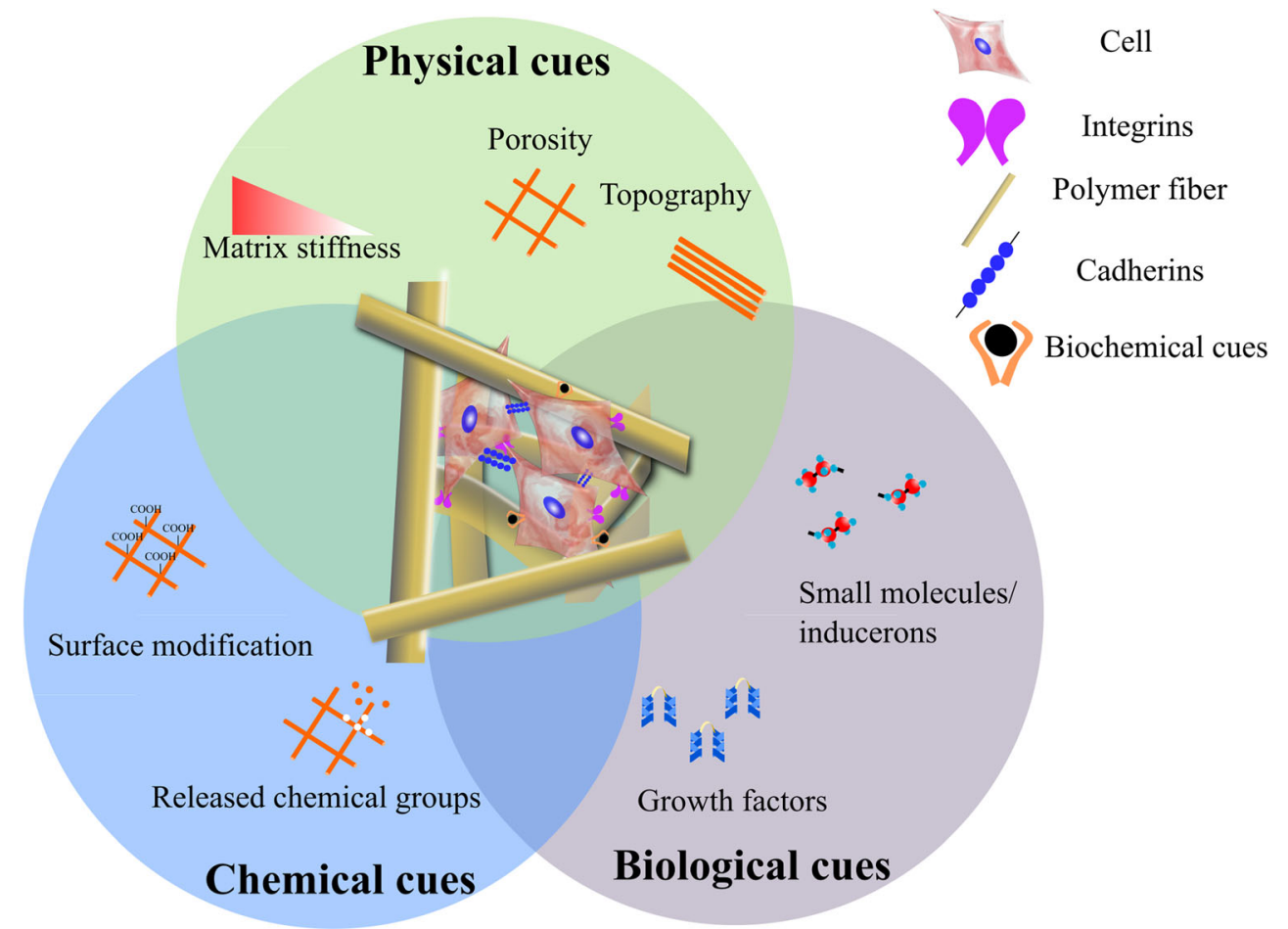


mechanical environments in which they reside. Cells can sense the changes in mechanical environments and initiate the mechanotransduction pathways, which subsequently alter intracellular biochemical signals and ultimately modify cell physiology [47-49]. Engler et al. have demonstrated that MSCs differentiate into osteogenic, myogenic, and neurogenic lineages in a manner dependent on matrix stiffness [60]. Swift et al. revealed that matrix stiffness directly influenced the levels of nucleoskeletal protein lamin-A, which contributed to lineage determination via the vitamin A/retinoic acid (RA) pathway [61]. In a recent study by Yang et al., it has been shown that human MSCs (hMSCs) possess mechanical memory stored in the Yes-associated protein (YAP) and transcriptional coactivator with PDZ-binding domain (TAZ) and previous mechanical environment affects their fate determination [62]. In addition to topography and stiffness, matrix porous structure including pore size and geometry is another important factor that affects the cell behavior. For example, the electrospun nanofiber scaffolds are highly porous but contain small pores which may potentially limit cell infiltration [63]. A great amount of research efforts have focused on controlling the porous structures of the electrospun scaffolds to facilitate cell migration and tissue in-growth [64, 65].

\section{Chemical Cues}

Incorporation of chemical cues in the form of specific chemical groups into materials influences cell behavior. Specific surface chemistry such as different terminal functionalities $\mathrm{CH}_{3}, \mathrm{OH}, \mathrm{COOH}$, and $\mathrm{NH}_{2}$ can be linked to material surfaces to achieve desirable cellular responses [1]. Surface functionalization of PCL nanofibers with carboxyl, carbonyl, and hydroxyl groups fostered myotube differentiation [66]. Encapsulation of hMSCs with acid-, phosphate-, and t-butylfunctionalized materials affected cellular phenotype and differentiation to osteogenic or adipogenic pathways [67]. Proper surface modification of monomer-grafted membrane with $\mathrm{N}$-[3-(dimethylamino)propyl] methacrylamide increased the attachment and expansion capacity of embryonic stem cells up to seven passages [68]. Scaffolds with lipid, lipophilic molecule, or chemically modified surface can modulate cell behavior [69]. Similarly, released chemical groups resulting from material degradation can affect cell survival and cell fate. For example, the released calcium and phosphate ions elicit an inductive effect on osteogenic differentiation of stem cells [70]. The application of high-throughput screening has facilitated the discovery and utilization of simple chemistries for optimized cell behaviors such as stem cell growth and differentiation $[68,71,72]$. In addition, surface-functionalized polymers have also been reported to enhance tissue integration. The presence of negatively charged functional groups on polymer surfaces induced formation of an apatite layer for improved osteointegration [39]. Chondroitin sulfate functionalized with aldehyde functional groups enhanced tissue integration for cartilage repair [73].

\section{Biological Cues}

Biological performance of materials can be enhanced with spatiotemporal presentation of various biological cues such as growth factors and small molecules/inducerons [74, 75]. These biological factors can be incorporated into a material through physical entrapment, ionic interactions, or covalent coupling [75]. So far, a variety of growth factors including bone morphogenetic proteins (BMPs), bFGF, vascular endothelial growth factor (VEGF), nerve growth factor (NGF), and platelet-derived growth factor (PDGF) have been well established in terms of triggering cellular signaling pathways to enhance therapeutic efficacy for musculoskeletal regenerative engineering [76, 77]. For example, BMPs are osteoinductive factors that are widely used to promote osteogenic differentiation and bone formation. To date, BMP-2 and BMP-7 have been approved by the Food and Drug Administration for a number of clinical applications including fracture healing, long bone defect repair, and spinal fusion [78]. Although growth factors show great promise, they are associated with various drawbacks such as protein instability, high manufacturing cost, and immunogenicity. Therapeutic small molecules $(<1000 \mathrm{Da})$ emerge as attractive alternative forms of bioactive factors [74]. Lo et al. have shown that stimulation of protein kinase A (PKA) signaling pathway by continuous administration of 6-Bnz-cAMP which is a PKAspecific cyclic adenosine monophosphate (cAMP) analog promoted in vitro osteogenesis in MC3T3-E1 and hMSCs [79]. Another attractive class of biological factors constitute simple signaling molecules (inducerons) that are capable of influencing cell behaviors via stimulating autocrine and paracrine secretion of related growth factors for inductive tissue regeneration $[80,81]$. We have recently demonstrated that the release of calcium and phosphate ions from calcium phosphate $(\mathrm{CaP})$ ceramics could directly induce the production of endogenous BMP-2 of human adipose-derived stem cells (ADSCs) [70]. Other inducerons include hydrogen peroxide $\left(\mathrm{H}_{2} \mathrm{O}_{2}\right)$ [82], nitric oxide (NO) [83], and hydrogen sulfide $\left(\mathrm{H}_{2} \mathrm{~S}\right)$ [84], which can effectively influence cell differentiation via inductive growth factor production. Engineering release of these inductive molecules opens up possibilities of long-term delivery through a wide variety of controlled release strategies as compared to the relatively fewer options available for fragile, expensive protein growth factors.

\section{Regenerative Applications}

So far, a large number of tissue-specific electrospun polymeric nanofiber scaffolds have been developed from different 
polymers, polymer blends or composites for regenerating bone [22, 28, 29, 85], soft tissues [19, 86-91], and tissue interfaces [92-94] (Table 2).

\section{Bone}

Bone constitutes an internal support system for all higher vertebrates. In orthopedic and reconstructive surgery, there is an increasing demand for repair and reconstruction of bone defects arising from trauma, degenerative pathology, and deformities. Sales of bone graft and bone graft substitutes in USA alone were 1.5 billion dollars in 2009 [98]. Autografts and allografts suffer from limited availability and potential immunogenicity, respectively. These drawbacks have led to the development of biocompatible regenerative scaffolds to repair and restore function of bone. An ideal bone graft substitute should possess osteoconductive, osteoinductive, and osseointegration characteristic properties [81, 99]. For example, scaffold porous structure should be engineered to facilitate the oxygen and nutrient transport as well as cell migration into the scaffold interior. Complete regeneration and functional restoration may be achieved when the bone graft is well integrated with the host, remodeled and replaced with native bone tissue at similar rates of graft degradation [100].

Rational design of a bone graft substitute requires an acute understanding of the composition of bone, its hierarchical architecture, its organization into the bone matrix, as well as cell-material interactions [81, 101]. Figure 4 illustrates the hierarchical structure of bone over different length scales [6]. Bone is a material comprised of hierarchically arranged collagen fibrils, hydroxyapatite (HA), and proteoglycans in the nanometer scale which provides an extracellular environment for the bone cells $[6,102]$. In specific, the individual collagen helical chains are $10 \mathrm{~nm}$ in length, which assemble into a fibrous structure with fiber bundles $(50-500 \mathrm{~nm}$ in diameter). The mineral component of bone is composed of plate-like HA crystals measuring about $20-80 \mathrm{~nm}$ in length. Thus, engineering of degradable scaffolds with such a natural environment would potentially favor cell performance to achieve enhanced bone regeneration.

Till date, polymeric biomaterials have been extensively investigated for the development of bone scaffolds [81]. In a seminal study, a PLGA (85:15) fiber scaffold with diameters ranging from $500-800 \mathrm{~nm}$ was fabricated by electrospinning and characterized for pore size distribution, porosity, and mechanical properties [18]. This scaffold was found to recapitulate the ECM and meet essential requirements of an ideal engineered scaffold. The cell-matrix interaction resulted in enhanced osteoblast adhesion and proliferation. This first report provided a foundation for the use of electrospun biodegradable scaffolds for tissue engineering based upon ECMmimicry architecture. To leverage synthetic flexibility, buffering and neutral degradation products, and biocompatibility of

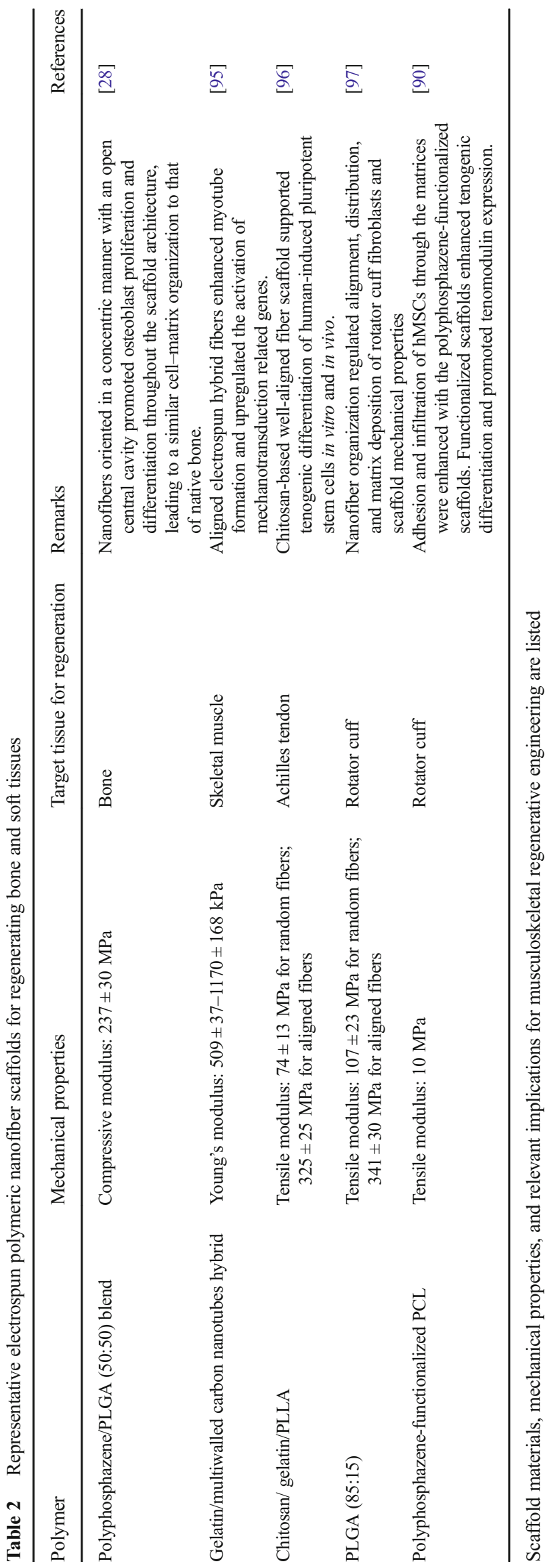


Fig. 4 Hierarchical organization of bone over different length scales where the macrostructure is composed of cortical and cancellous bone, which is composed of osteons with Haversian systems and lamellae [6]. This microstructure consists of collagen fibers made up of nanodiameter collagen fibrils. The smallest structural unit in bone is bone mineral crystals, collagen molecules, and noncollagenous proteins

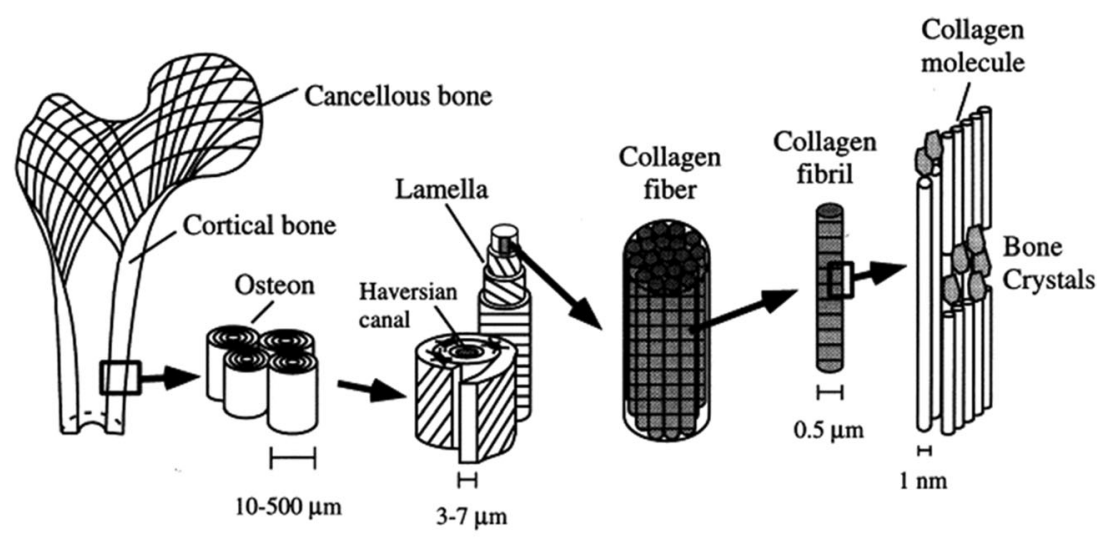

Microstructure
Nanostructure
Macrostructure
Sub-microstructure
Sub-nanostructure polyphosphazenes, our research work has focused on development of biodegradable polyphosphazenes as a unique class of electrospun nanofiber scaffolds for bone regeneration [22, $28,85,103]$. Inspired by the hierarchical architecture that enables bone function, we have developed a mechanically competent 3D scaffold system mimicking the bone marrow cavity, as well as the lamellar structure of bone by orienting electrospun dipeptide-based polyphosphazene/PLGA (50:50) blend nanofibers in a concentric manner with an open central cavity (Fig. 5) [28]. The biomimetic scaffold exhibited a similar characteristic mechanical behavior to that of native bone. Compressive modulus of the scaffold was found to be within the range of human trabecular bone. In vitro studies using primary cell culture demonstrated the ability of the biomimetic scaffold to support the osteoblast proliferation and accelerated differentiation throughout the scaffold architecture, which resulted in a similar cell-matrix organization to that of native bone and maintenance of structure integrity. Future work will focus on the in vivo investigation of such concentric open macrostructures of nanofibers that structurally and mechanically mimic the native bone as a potential scaffold design for accelerated bone healing. Other synthetic polymers including PCL and PLA have also been explored for bone engineering applications. For example, in vivo implantation of PCL fibers in rats for 4 weeks showed bone-like matrix formation and presence of collagen I, which exemplified the potential of PCL nanofibers in bone tissue engineering [104]. Nanofibers of PLA with varying diameters were found to affect the morphology and proliferation of MC3T3-E1 cells in a different manner [105]. Blend nanofibers of PLA and gelatin resulted in greater cellular growth than pure PLA nanofibers [106]. Multiscale porous PLA fibrous scaffolds were also developed with various dimensions and the efficacy of blending of different scale fibers in a single system was evaluated [107].

The ECM-mimicking environment generated by nanofibers enables an effective means to modulate cellular response toward the initiation of cell adhesion followed by cell growth, differentiation, and mineralization [108, 109]. Considerable research efforts have been focused on development of nanofiber matrices with appropriate surface properties to enhance cell adhesion toward matrix mineralization for bone
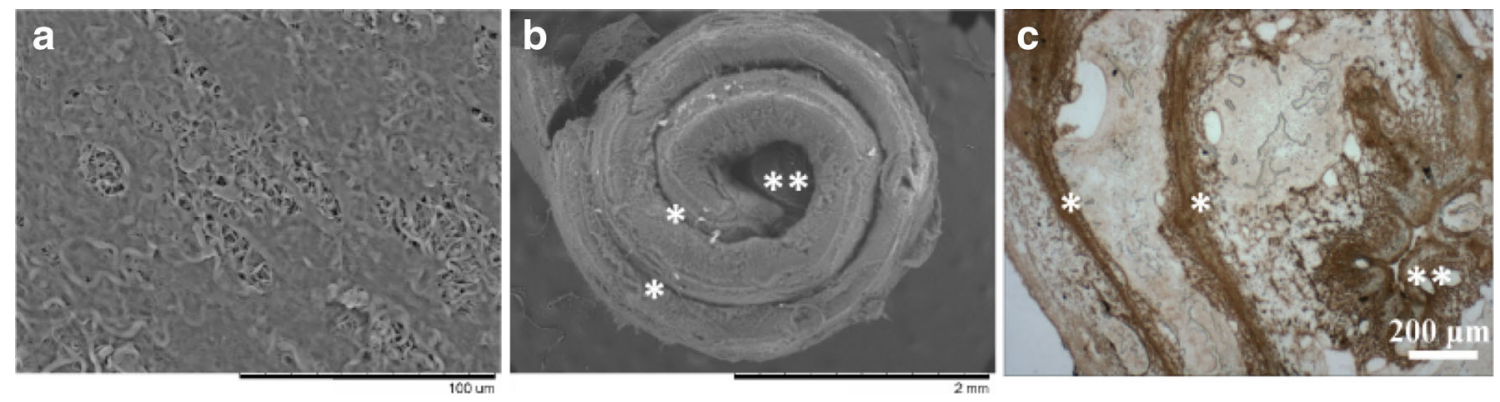

Fig. 5 Biomimetic scaffolds comprised of electrospun nanofibers of dipeptide-based polyphosphazene-polyester blends mimicking the collagen fibrils present in native bone ECM [28]. a SEM image showing osteoblasts covering the blend nanofiber surface with a wellspread morphology by day 3. b SEM image illustrating the morphologies of cell-seeded 3D biomimetic scaffolds after 28 days of culture. c Immunohistochemical staining for osteopontin (OPN), a prominent component of the mineralized ECM, illustrating a homogenous ECM distribution throughout the scaffold architecture at day 28. Single asterisk indicates interlamellar space whereas two asterisks indicate central cavity 
regeneration. The cellular responses on synthetic nanofibers can be enhanced through surface modification. For example, the wettability of the fibers can be improved by mineralizing the surface of the nanofibers [110]. Surface-mineralized scaffolds showed predominantly higher rate of water absorptivity and enhanced cell attachment on murine-derived osteoblastic cells. PCL nanofibers with apatite deposition supported elevated gene expression for collagen I, Runx2, and osteocalcin when compared to PCL nanofibers. A different route to surface functionalize the polymeric fibers involves the use of Arg-Gly-Asp (RGD) peptide [111]. Surface functionalization of PLA nanofibers with RGD was achieved using plasma treatment in combination with 1-ethyl-3-[3-dimethylaminopropyl]carbodiimide (EDC)/Nhydroxysulfosuccinimide (Sulfo-NHS) activation. The functionalized nanofibers mediated the expression of osteocalcin by hMSCs.

Degradable polymers have been combined with bioactive ceramics such as HA and tricalcium phosphate (TCP) to form composite scaffolds for bone regeneration because the inorganic phase is primarily composed of HA [112-114]. The disadvantages such as brittleness and low flexibility inherited with ceramics could be overcome by combining them with polymers to form composite matrices $[81,115,116]$. The presence of polymers enhances the in situ degradation of materials with respect to the cell infiltration and tissue in-growth. Schneider et al. prepared nanofiber composites consisting of PLGA (85:15) and amorphous TCP nanoparticles by lowtemperature electrospinning [117]. In a 6-mm critical-sized cranial defect model in New Zealand white rabbits, implantation of TCP-containing PLGA fiber scaffolds resulted in a significant increase in the area fraction of newly formed bone 4-week postimplantation as compared to pure PLGA fiber scaffolds. The combination of PCL with calcium carbonate was used to obtain composite nanofibers for guided bone regeneration [118]. PCL and calcium carbonate were mixed in two different ratios and electrospun to produce composite fibers. Both composite fibers supported the osteoblast attachment and proliferation which indicated their potential use in guided bone regeneration. Tan et al. reported the production of randomly dispersed crystalline $\mathrm{CaP}$ nanofibers by sol-gel method in combination with electrospinning technique [119]. Nanofibers could be designed as hollow, solid, or calcium phosphate shell surrounding a polymer. The inner core could contain biologically functional additives for any kind of tissue development functionalities. Such nanofibers can be used for culturing bone and dental cells and for tissue regeneration to treat bone, dental or periodontal diseases and defects. Nanofibers have also been prepared with bioactive glass [120,121] and silicates [122] for bone engineering applications.

Delivery of biological factors to direct cell behavior and tissue regeneration using nanofibers is another attractive strategy for accelerated bone healing due to high surface area and nanotextured features of nanofibers [123-125]. Li et al. reported the development of silk fibroin fiber scaffolds containing BMP-2 and/or nanoparticles of HA (nHA) by electrospinning [126]. BMP-2 incorporated fibers showed higher calcium deposition and enhanced transcript levels of bone-specific markers of hMSCs as compared to the controls. The incorporation of HA resulted in enhanced mineralization on composite scaffolds which may be due to the synergistic effect of BMP-2 and HA. In another study, BMP-2-loaded PLGA (50:50)/nHA composite fiber scaffolds were fabricated through either encapsulation into fibers during electrospinning or coating on fiber surface after electrospinning [127]. In vivo evaluation with the PLGA/nHA composite scaffolds using a tibia nude defect model in mouse resulted in enhanced new bone formation and healing of segmental defects indicating the bioactivity of released BMP-2 [128]. Schofer et al. studied the efficacy of BMP-2 incorporation into PLA nanofibers in healing critical-sized calvarial defects of adult male SpragueDawley rats [35]. The PLA/BMP-2 implants supported faster bone regeneration to close bone defects within 8 weeks. Similarly, an enhanced healing effect was observed with BMP-2 released from a PLA/collagen nanofiber composite matrix with nHA [129].

\section{Tendon}

Tendons connect muscles and bones and function to enable locomotion and joint stability [130]. Normal tendon is composed of soft and fibrous connective tissue that consists of densely packed collagen fiber bundles aligned parallel to the longitudinal tendon axis, and spindle-shaped fibroblast-like cells (tenocytes) within this organized ECM. Injuries to the soft tissue including tendon and ligament account for $50 \%$ of the total musculoskeletal injuries reported in the USA per year. The tendon injuries occur either by trauma or by repetitive mechanical loading [131]. The tendon repair process is slow and associated with varied outcomes. The repaired tissue is often inferior to the natural tendon and thus fails to restore functionality [132]. Large tendon gap defects must be reconstructed and augmented with suitable grafts. Autografts and allografts suffer from shortcomings such as availability and potential immune rejection. Therefore, there is a great need for the development of engineered tendon that is biomechanically, biochemically, and histologically similar to the native tissue. Biodegradable polymers have been extensively studied in the form of 3D scaffolds to restore the native tendon ECM composition, structure, and tissue morphology [97, 133, 134]. Regenerative engineering provides an integrated technology toolbox to make important steps forward in understanding the biology and organization of the native tendon and the process of morphogenesis of tendon tissue [1,135]. Ideal scaffolds used for tendon repair should mimic the architecture of native 
tendon ECM. They should be biodegradable, biocompatible, and mechanically suitable. The degradation rate of scaffolds must be compatible with the rate of neotissue growth so that the regeneration is completed when the scaffolds completely degrade. Furthermore, scaffolds should be able to support efficient tendogenesis both in vitro and in vivo [136, 137].

Collagen is one of the most widely used scaffold materials for tendon engineering due to its abundance in tendons [138]. It shows superior biofunctionality and biocompatibility and can support cell adhesion and proliferation. Collagen-based gels and sponges are two different types of scaffolds used in tissue engineering. A combination of both enhanced the cell proliferation and tendogenesis [139]. However, there are a number of concerns over the use of collagen materials resulting from limited processability and mechanical strength. Thus, collagen is used in combination with other polymers to produce tendon scaffolds [140]. For example, blend nanofibers composed of PLA and collagen had a positive effect on the gene expression of collagen I, III, X, and decorin, which indicated possible involvement of focal adherence kinases [141]. Polysaccharides represent an important class of natural polymers owing to biofunctionality and the presence of glycosaminoglycan units. In particular, chitosan has been widely used for tendon repair alone or in combination with other polymers. For example, chitosan/hyaluronan hybrid fibers showed enhanced production of type I collagen by seeded fibroblasts as well as improved mechanical strength in the regenerated tissues of the rotator cuff in rabbits [142].

Synthetic polymer-based approach is beneficial to achieve the required mechanical properties and flexibility while avoiding the inferior processability existing with natural polymers. We have previously developed 3D braided fiber scaffolds for use as graft materials in ligament and tendon repair, reconstruction, and replacement [143]. In order to identify proper cell source, cells derived from various ligaments and tendons were cultured on a 3D braided PLA fibrous scaffold and characterized for differential proliferation and differentiation [144]. Our recent research efforts have focused on the development of electrospun nanofibers for tendon engineering from various degradable polymers such as polyesters [87, 145] and polyphosphazenes [90,91]. Taylor et al. investigated the potential of using electrospun PLGA (85:15) scaffolds with appropriate cellular and biomechanical properties to support and accelerate the healing of a torn rotator cuff in adult Sprague-Dawley rats [87]. Peach et al. investigated the feasibility of using poly[(ethyl alanato $\left.)_{1}(p \text {-methyl phenoxy })_{1}\right]$ phosphazene (PNEA-mPh) to modify the surface of electrospun PCL nanofiber matrix [91]. Surface functionalization with PNEA-mPh significantly increased the PCL matrix hydrophilicity. An in vitro study was conducted to examine the effect of surface functionalization with PNEA-mPh on hMSC adhesion, cellconstruct infiltration, proliferation and tendon differentiation, as well as long-term cellular construct mechanical properties [90]. Functionalized matrices showed a rough surface morphology and greater cell-construct infiltration as compared to smooth PCL fiber matrices. Furthermore, functionalized matrices supported an enhanced tenogenic differentiation, possessing greater tenomodulin expression and superior phenotypic maturity. This study confirms that functionalization is an efficient method for improving cell interactions on PCL nanofibers for tendon repair. Aligned electrospun scaffolds that mimic not only the fiber bundle size of the tendon ECM but also the parallel architectural arrangement are conducive for favorable cellular responses under appropriate chemical and mechanical stimuli. Braided nanofiber scaffolds were fabricated by braiding aligned bundles of electrospun PLA nanofibers to provide an appropriate mechanical and structural environment for cellular activity [146]. This scaffold design enabled an additional degree of flexibility to tune the mechanical properties of individual scaffolds. In brief, highly aligned nanofibers with an average diameter of $702 \pm 205 \mathrm{~nm}$ were collected on a rotating mandrel and processed into aligned nanofiber bundles which were subsequently used to fabricate braided scaffolds according to the braiding patterns. The braided scaffolds exhibited the triphasic mechanical behavior of native tendon. The braided scaffolds supported the cell attachment, proliferation, and tenogenic differentiation of hMSCs in the presence of mechanical stimulation in a bioreactor.

Biological factors also play an important role in proliferation and tenogenic differentiation of cells. James et al. fabricated a nanofiber scaffold from PLGA (65:35) mimicking the tendon collagen fiber bundles and studied the effect of growth differentiation factor-5 (GDF-5) on cell proliferation and gene expression by primary rat ADSCs on the nanofiber scaffold [88]. The tensile strength of the scaffold was comparable to that of human flexor digitorum tendons under passive and active unresisted flexion-extension. The electrospun nanofiber scaffold supported the adhesion and proliferation of ADSCs. In response to treatment with GDF-5, a dense layer of ADSCs covered the scaffold surface after 14 days with only few fibers visible. Furthermore, GDF-5 treatment resulted in upregulation of gene expression of scleraxis, the neotendon marker in ADSCs cultured on the electrospun PLGA scaffold. Current ongoing work focuses on characterization of the healing response in a rat Achilles tendon gap defect model that simulates a lacerated tendon with this scaffold delivering either ADCSs or surface immobilized GDF-5. Similarly, combining aligned chitosan-PCL nanofibers with transforming growth factor- $\beta 3$ enhanced differentiation of hMSCs into tenogenic progenitors [147]. In another study, a layered electrospun PLGA $(85: 15)$ nanofiber scaffold was developed in combination with a heparin/fibrin-based delivery system (HBDS) to deliver PDGF-BB and adiposederived MSCs for tendon repair [148]. A uniaxial array of 
the PLGA nanofibers with diameters of $400-700 \mathrm{~nm}$ was designed to mimic the anisotropic tendon ECM and provide mechanical integrity for implantation, whereas the HBDS enabled the controlled delivery of PDGF-BB and MSCs (Fig. 6). In vitro studies confirmed viability of the cells as well as sustained growth factor release. The potential of the scaffold for flexor tendon repair was investigated in a clinically relevant canine animal model. It was demonstrated that the scaffold was biocompatible and the delivered MSCs remained viable for at least 9 days postoperatively.

\section{Skeletal Muscle}

Skeletal muscles account for more than $30 \%$ of total body mass. The structure of muscle tissue is composed of oriented muscle fibers that are formed by the fusion of myoblasts. This orientation in fiber alignment enables an anisotropic organization of muscle tissue ECM for functional contraction, which leads to body movement. Following injuries, the resident satellite cells are activated to help regenerate the skeletal muscles [149]. The regenerative capacity of skeletal muscles is severely compromised resulting from large muscle loss due to trauma, surgery, or disease. Currently, the primary practiced treatment involves the transplantation of functional skeletal muscle (e.g., muscle flaps) from other areas of the body [150]. However, this treatment option is hindered by muscle tissue availability and donor site morbidity. Cell therapies involving the injection of exogenous myogenic cells, satellite cells, and myoblasts have been investigated with limited success due to low cell survival rate [151]. These limitations associated with current treatments highlight the need for the development of an innovative strategy to generate functional skeletal muscle tissues [150].

Muscle regenerative engineering focuses on design and development of artificial structures that mimic the morphology and function of native skeletal muscle to facilitate muscle growth and regeneration. A functional biodegradable scaffold
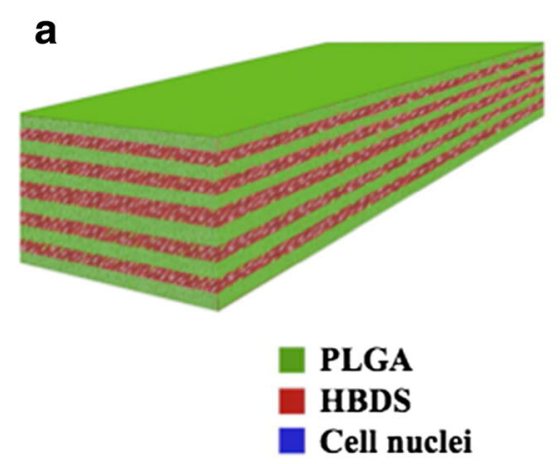

Fig. 6 A layered nanofiber scaffold design for tendon repair [148]. a A schematic of the layered scaffold with 11 alternating layers of aligned electrospun PLGA nanofibers separated by HBDS containing MSCs. b Micrograph of the layered scaffold cultured in vitro where the PLGA plays a crucial role in the efficacy of bioengineered constructs for skeletal muscle regeneration. The biodegradable nanofiber scaffold should be biocompatible and offers a temporary ECM environment to direct the morphogenesis and development of engineered muscle, which will be gradually replaced by the newly formed skeletal muscle tissue. The degradation rate of the scaffold should match the rate of tissue formation and regeneration. Given the directionality in skeletal muscle, the scaffold should facilitate efficient organization of muscle cells to form aligned myotubes during muscle regeneration [152]. In addition to biocompatibility, biodegradability, and the ability to support cell functions, there are several important specific scaffold design parameters that need to be considered for skeletal muscle engineering. The scaffold should be mechanically suitable to support functions of skeletal muscle. Different myoblast responses on PLGA (50:50)/PLA blend scaffold with varying stiffness highlighted the importance of mechanical microenvironment on muscle development [59]. An optimal matrix elasticity is required for myoblast differentiation in culture [9]. Culturing isolated satellite cells on a matrix with stiffness matching their in vivo niche resulted in improved engraftment and healing after transplantation [153, 154]. Additionally, scaffold conductivity has been reported to be beneficial for electrical stimulation to ensure synchronization of skeletal muscle contractions [155].

The flexibility of electrospinning process allows for the creation of aligned fiber scaffolds from various polymers that mimic skeletal muscle orientation and provide the necessary ECM cues to guide cellular organization. Aligned PLA nanofibers have been shown to promote cell and cytoskeleton alignment, myotube assembly, myotube striation, and myoblast proliferation, which supported the rationale of using nanofiber scaffolds for muscle engineering [56]. Studies with $\mathrm{PCL} /$ collagen blend nanofibers have demonstrated the benefits of unidirectional fiber orientation by facilitating alignment of human skeletal muscle cells and myotube formation [156]. In our recent work, we have fabricated aligned PLGA (85:15)

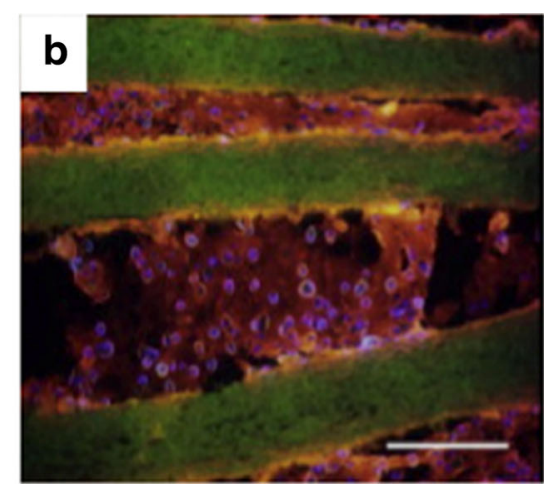

nanofibers, the HBDS, and the cell nuclei were labeled with FITC (green), Alexa Fluor 546 (red), and Hoechst 33258 (blue), respectively (scale bar: $200 \mu \mathrm{m}$ ) 
nanofibers ranging from nanoscale $(\sim 300 \mathrm{~nm})$ to microscale $(\sim 3 \mu \mathrm{m})$ via electrospinning $[157,158]$. SEM micrograph in Fig. 7a shows the representative morphology of aligned PLGA fibers mimicking oriented muscle fibers. In vitro studies were conducted by seeding $\mathrm{C} 2 \mathrm{C} 12$ myoblasts onto these fiber matrices followed by systematic analysis of cellular responses. The aligned fiber matrices supported cell adhesion and alignment demonstrating the effect of contact guidance (Fig. 7b) [152, 159]. Further, aligned fibers with varying diameters resulted in different responses in cell attachment and proliferation, indicating the role of cell topography sensing in cell-biomaterial interactions. Current ongoing studies focus on elucidating the cell signaling pathway governing cell topography sensing and optimizing the scaffold properties for enhanced myogenic differentiation and in situ muscle regeneration. In addition to orientation of fiber scaffolds, material characteristics involving surface chemistry also play key roles in muscle tissue development [66]. In vitro study with $\mathrm{C} 2 \mathrm{C} 12$ cells demonstrated that a combination of fiber orientation and an oxygen functional hydrocarbon layer resulted in the highest degree of cellular alignment and myotube formation as well as sarcomeric striation and contractility.

In addition, electrical stimulation has a beneficial effect for skeletal muscle engineering. In that direction, a variety of polymer composites have been developed to obtain unique conductive and electric properties by combining polymers with metal nanoparticles [160] and carbon nanotubes [161, 162]. For example, McKeon-Fischer et al. developed an electrospun scaffold through the combination of PCL with multiwalled carbon nanotubes and a hydrogel consisting of polyvinyl alcohol and polyacrylic acid as a potential nanoactuator for skeletal muscle engineering [162]. Electrical conductive PCL/polyaniline blend electrospun fibers have also been reported for improving skeletal muscle regeneration potential [163]. Electroactive nanocomposites composed of PLGA (50:50) nanofibers incorporated with multiwalled carbon nanotubes enhanced mechanical and electrical conductivity for skeletal muscle tissue engineering [164]. These composites supported improved mature myotube formation of $\mathrm{C} 2 \mathrm{C} 12$ cells as compared to PLGA scaffolds.

\section{Tissue Interfaces}

Tissue interfaces between bone and soft tissues (e.g., tendon/ ligament) are characterized by unique multitissue transition and gradients of composition and functional properties in a continuous phase. Integration of these individual tissues into complex tissues or organs presents many engineering and biological challenges. In recent years, functional scaffolds with gradient have been developed for interface regeneration [92, 165-167]. For example, Li et al. prepared a linear gradient of calcium phosphate coating on PCL and PLGA (85:15) nanofibers via a biomineralization process for mimicking the gradual increase of mineralization in tendon-to-bone insertion site [94]. Recent in vitro studies of PLGA (85:15) nanofiber scaffolds, with spatial gradients in mineral content, suggested that osteogenesis of adipose-derived MSCs was positively correlated with the mineral content, resulting in a similar spatial gradient of cell phenotypes in the native enthesis [93]. Lu's research group developed a PLGA/nHA nanofiber composite system and demonstrated the potential of combining the composite scaffolds with relevant cell types such as fibroblasts, osteoblasts, and chondrocytes to regenerate both the nonmineralized and mineralized fibrocartilage regions of the supraspinatus tendon-to-bone insertion site [92].

Developmental biology provides insights into biological processes during the formation, maintenance, degeneration, and regeneration of tissues or organs. The emphasis of a regenerative engineering approach is directed toward studying the role of various physicochemical and biological cues on cellular activity and capitalizing on the plasticity of the cells for complex tissue regeneration. A recent study demonstrated the possibility of guiding differentiation of hMSCs into ligament fibroblast-like cells through the control of scaffold

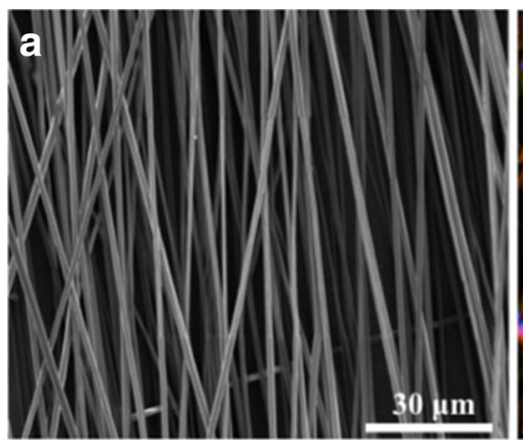

Fig. 7 Aligned electrospun fiber matrices for skeletal muscle regeneration. a SEM micrograph showing the morphology of aligned PLGA fibers (fiber diameter $\sim 1300 \mathrm{~nm}$ ). b Representative cell alignment $24 \mathrm{~h}$ after seeding on aligned PLGA fibers. Cells spread

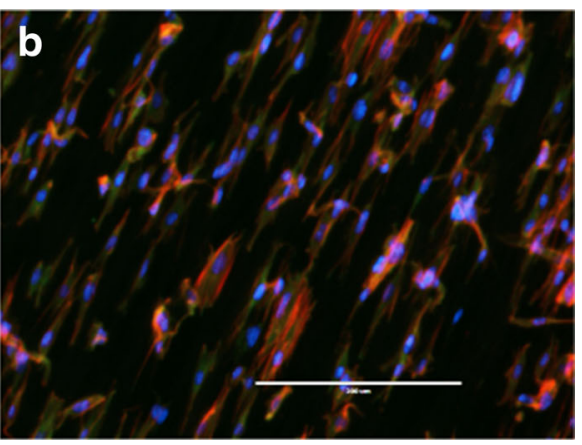

along the direction of fiber orientation on aligned scaffolds indicating the effect of contact guidance. Red: cytoskeletal actin, green: vinculin, and blue: DAPI 
alignment and mechanical stimulation without the use of chemical stimuli [168]. Regenerative efficacy of biomimetic integrated graft systems for regeneration of complex tissues greatly depends on the ability to elicit precise control over stem cells into distinct lineages while maintaining a continuous tissue phase.

\section{Conclusions and Future Outlook}

Regenerative engineering is an emerging interdisciplinary field, which combines different disciplines such as materials science, chemistry, cell biology, bioengineering, and medicine. It aims to develop functional biological tissue substitutes by engineering 3D biodegradable artificial ECM with appropriate physical, chemical, and biological properties. Electrospinning of polymers provides a versatile technology platform to create nanostructures that mimic the native tissue hierarchical structures. Much progress has been made on the development of tissue-specific scaffolds from a variety of degradable biomaterials including synthetic and natural polymers as evidenced from the promising results of the studies mentioned above. Nevertheless, several biological and engineering challenges remain for electrospun nanofibrous scaffolds to make a significant clinical impact for musculoskeletal tissue regeneration. The tissues in the human body are incredibly complex with 3D hierarchical structures, anisotropic properties, and cell heterogeneity. Development of 3D nanofibrous scaffolds that possess all of the properties necessary to mimic musculoskeletal tissues while eliciting precise regulatory control of specific populations of cells is paramount in achieving successful translation in the clinic. The integration of physical, chemical, and biological cues into biomaterials will facilitate the translational efforts through a further understanding of effects of distinct material properties on cell-biomaterial interactions as well as close collaboration among chemists, biologists, chemical engineers, material scientists, and clinicians.

Acknowledgements Funding support from Showalter Trust, Purdue Research Foundation, and Purdue Start-up Package is greatly appreciated.

\section{References}

1. Deng M, James R, Laurencin CT, Kumbar SG. Nanostructured polymeric scaffolds for orthopaedic regenerative engineering. IEEE Trans Nanobioscience. 2012;11:3-14.

2. Laurencin CT, Khan Y. Regenerative engineering. Sci Transl Med. 2012;4:160ed9.

3. Reichert WM, Ratner BD, Anderson J, Coury A, Hoffman AS, Laurencin CT, et al. 2010 Panel on the biomaterials grand challenges. J Biomed Mater Res A. 2011;96:275-87.

4. Kumbar S, Laurencin C, Deng M. Natural and synthetic biomedical polymers: Newnes. 2014.
5. Nair LS, Laurencin CT. Biodegradable polymers as biomaterials. Prog Polym Sci. 2007;32:762-98.

6. Rho J-Y, Kuhn-Spearing L, Zioupos P. Mechanical properties and the hierarchical structure of bone. Med Eng Phys. 1998;20:92102.

7. Athanasiou K, Zhu C-F, Lanctot D, Agrawal C, Wang X. Fundamentals of biomechanics in tissue engineering of bone. Tissue Eng. 2000;6:361-81.

8. Wren TA, Yerby SA, Beaupré GS, Carter DR. Mechanical properties of the human Achilles tendon. Clin Biomech. 2001;16:24551.

9. Engler AJ, Griffin MA, Sen S, Bönnemann CG, Sweeney HL, Discher DE. Myotubes differentiate optimally on substrates with tissue-like stiffness pathological implications for soft or stiff microenvironments. J Cell Biol. 2004;166:877-87.

10. Morrow DA, Haut Donahue TL, Odegard GM, Kaufman KR. Transversely isotropic tensile material properties of skeletal muscle tissue. J Mech Behav Biomed Mater. 2010;3:124-9.

11. Shepherd D, Seedhom B. The 'instantaneous' compressive modulus of human articular cartilage in joints of the lower limb. Rheumatology. 1999;38:124-32.

12. Jiang T, Deng M, James R, Nair LS, Laurencin CT. Micro-and nanofabrication of chitosan structures for regenerative engineering. Acta Biomater. 2014;10:1632-45.

13. Deng M, Kumbar SG, Wan Y, Toti US, Allcock HR, Laurencin CT. Polyphosphazene polymers for tissue engineering: an analysis of material synthesis, characterization and applications. Soft Matter. 2010;6:3119-32.

14. Dvir T, Timko BP, Kohane DS, Langer R. Nanotechnological strategies for engineering complex tissues. Nat Nanotechnol. 2011;6:13-22.

15. Dahlin RL, Kasper FK, Mikos AG. Polymeric nanofibers in tissue engineering. Tissue Eng Part B Rev. 2011;17:349-64.

16. Huang ZM, Zhang YZ, Kotaki M, Ramakrishna S. A review on polymer nanofibers by electrospinning and their applications in nanocomposites. Composites Sci Technol. 2003;63:2223-53.

17. Formhals A. Process and apparatus for preparing artificial threads US patent 1,975,5041934.

18. Li WJ, Laurencin CT, Caterson EJ, Tuan RS, Ko FK. Electrospun nanofibrous structure: a novel scaffold for tissue engineering. $\mathrm{J}$ Biomed Mater Res. 2002;60:613-21.

19. Kumbar SG, Nukavarapu SP, James R, Nair LS, Laurencin CT. Electrospun poly (lactic acid-co-glycolic acid) scaffolds for skin tissue engineering. Biomaterials. 2008;29:4100-7.

20. Shalumon K, Sathish D, Nair S, Chennazhi K, Tamura H, Jayakumar R. Fabrication of aligned poly (lactic acid)-chitosan nanofibers by novel parallel blade collector method for skin tissue engineering. J Biomed Nanotechnol. 2012;8:405-16.

21. Xie J, MacEwan MR, Ray WZ, Liu W, Siewe DY, Xia Y. Radially aligned, electrospun nanofibers as dural substitutes for wound closure and tissue regeneration applications. ACS Nano. 2010;4:5027-36.

22. Bhattacharyya S, Kumbar SG, Khan YM, Nair LS, Singh A, Krogman NR, et al. Biodegradable polyphosphazenenanohydroxyapatite composite nanofibers: scaffolds for bone tissue engineering. J Biomed Nanotechnol. 2009;5:69-75.

23. Zhang Y, Venugopal JR, El-Turki A, Ramakrishna S, Su B, Lim CT. Electrospun biomimetic nanocomposite nanofibers of hydroxyapatite/chitosan for bone tissue engineering. Biomaterials. 2008;29:4314-22.

24. Shim IK, Suh WH, Lee SY, Lee SH, Heo SJ, Lee MC, et al. Chitosan nano-/microfibrous double-layered membrane with rolled-up three-dimensional structures for chondrocyte cultivation. J Biomed Mater Res A. 2009;90:595-602.

25. Pham QP, Sharma U, Mikos AG. Electrospun poly $(\varepsilon-$ caprolactone) microfiber and multilayer nanofiber/microfiber 
scaffolds: characterization of scaffolds and measurement of cellular infiltration. Biomacromolecules. 2006;7:2796-805.

26. Pakravan M, Heuzey M-C, Ajji A. Core-shell structured PEOchitosan nanofibers by coaxial electrospinning. Biomacromolecules. 2012;13:412-21.

27. Jiang Y-N, Mo H-Y, Yu D-G. Electrospun drug-loaded core-sheath $\mathrm{PVP} /$ zein nanofibers for biphasic drug release. Int J Pharm. 2012;438:232-9.

28. Deng M, Kumbar SG, Nair LS, Weikel AL, Allcock HR, Laurencin CT. Biomimetic structures: biological implications of dipeptide-substituted polyphosphazene-polyester blend nanofiber matrices for load-bearing bone regeneration. Adv Funct Mater. 2011;21:2641-51.

29. Wang J, Valmikinathan CM, Liu W, Laurencin CT, Yu X. Spiralstructured, nanofibrous, 3D scaffolds for bone tissue engineering. J Biomed Mater Res A. 2010;93:753-62.

30. Wang Y, Shi H, Qiao J, Tian Y, Wu M, Zhang W, et al. Electrospun tubular scaffold with circumferentially aligned nanofibers for regulating smooth muscle cell growth. ACS Appl Mater Interfaces. 2014;6:2958-62.

31. Amruthwar SS, Janorkar AV. In vitro evaluation of elastin-like polypeptide-collagen composite scaffold for bone tissue engineering. Dent Mater. 2013;29:211-20.

32. Li Z, Ramay HR, Hauch KD, Xiao D, Zhang M. Chitosan-alginate hybrid scaffolds for bone tissue engineering. Biomaterials. 2005;26:3919-28.

33. Jiang T, Nukavarapu SP, Deng M, Jabbarzadeh E, Kofron MD, Doty SB, et al. Chitosan-poly(lactide-co-glycolide) microspherebased scaffolds for bone tissue engineering: In vitro degradation and in vivo bone regeneration studies. Acta Biomater. 2010;6: 3457-70.

34. Kumbar S, Toti U, Deng M, James R, Laurencin C, Aravamudhan A, et al. Novel mechanically competent polysaccharide scaffolds for bone tissue engineering. Biomed Mater. 2011;6:065005.

35. Schofer MD, Roessler PP, Schaefer J, Theisen C, Schlimme S, Heverhagen JT, et al. Electrospun PLLA nanofiber scaffolds and their use in combination with BMP-2 for reconstruction of bone defects. PLoS One. 2011;6:e25462.

36. Cao H, Kuboyama N. A biodegradable porous composite scaffold of $\mathrm{PGA} /$ beta-TCP for bone tissue engineering. Bone. 2010;46:386-95.

37. Yeo M, Lee H, Kim G. Three-dimensional hierarchical composite scaffolds consisting of polycaprolactone, $\beta$-tricalcium phosphate, and collagen nanofibers: fabrication, physical properties, and in vitro cell activity for bone tissue regeneration. Biomacromolecules. 2010;12:502-10.

38. Borden M, Attawia M, Khan Y, El-Amin S, Laurencin C. Tissueengineered bone formation in vivo using a novel sintered polymeric microsphere matrix. Bone Joint J. 2004;86:1200-8.

39. Jabbarzadeh E, Deng M, Lv Q, Jiang T, Khan YM, Nair LS, et al. VEGF-incorporated biomimetic poly (lactide-co-glycolide) sintered microsphere scaffolds for bone tissue engineering. J Biomed Mater Res B Appl Biomater. 2012;100:2187-96.

40. Deng M, Nair LS, Nukavarapu SP, Jiang T, Kanner WA, Li X, et al. Dipeptide-based polyphosphazene and polyester blends for bone tissue engineering. Biomaterials. 2010;31:4898-908.

41. Deng M, Nair LS, Nukavarapu SP, Kumbar SG, Jiang T, Krogman NR, et al. Miscibility and in vitro osteocompatibility of biodegradable blends of poly[(ethyl alanato) (p-phenyl phenoxy) phosphazene] and poly(lactic acid-glycolic acid). Biomaterials. 2008;29:337-49.

42. Deng M, Nair LS, Nukavarapu SP, Kumbar SG, Brown JL, Krogman NR, et al. Biomimetic, bioactive etheric polyphosphazene-poly(lactide-co-glycolide) blends for bone tissue engineering. J Biomed Mater Res A. 2010;92A:114-25.
43. Blanpain C, Lowry WE, Geoghegan A, Polak L, Fuchs E. Selfrenewal, multipotency, and the existence of two cell populations within an epithelial stem cell niche. Cell. 2004;118:635-48.

44. Kuang S, Gillespie MA, Rudnicki MA. Niche regulation of muscle satellite cell self-renewal and differentiation. Cell Stem Cell. 2008;2:22-31.

45. Morrison SJ, Scadden DT. The bone marrow niche for haematopoietic stem cells. Nature. 2014;505:327-34.

46. Yin H, Price F, Rudnicki MA. Satellite cells and the muscle stem cell niche. Physiol Rev. 2013;93:23-67.

47. Arnold M, Cavalcanti-Adam EA, Glass R, Blümmel J, Eck W, Kantlehner M, et al. Activation of integrin function by nanopatterned adhesive interfaces. ChemPhysChem. 2004;5:383-8.

48. Murphy WL, McDevitt TC, Engler AJ. Materials as stem cell regulators. Nat Mater. 2014;13:547-57.

49. Wen JH, Vincent LG, Fuhrmann A, Choi YS, Hribar KC, TaylorWeiner $\mathrm{H}$, et al. Interplay of matrix stiffness and protein tethering in stem cell differentiation. Nat Mater. 2014;13:979-87.

50. von der Mark K, Park J, Bauer S, Schmuki P. Nanoscale engineering of biomimetic surfaces: cues from the extracellular matrix. Cell Tissue Res. 2010;339:131-53.

51. Venugopal J, Vadgama P, Kumar TS, Ramakrishna S. Biocomposite nanofibres and osteoblasts for bone tissue engineering. Nanotechnology. 2007;18:055101.

52. Kim HW, Song JH, Kim HE. Bioactive glass nanofiber-collagen nanocomposite as a novel bone regeneration matrix. J Biomed Mater Res A. 2006;79:698-705.

53. Kong YP, Tu CH, Donovan PJ, Yee AF. Expression of Oct4 in human embryonic stem cells is dependent on nanotopographical configuration. Acta Biomater. 2013;9:6369-80.

54. Dalby MJ, Gadegaard N, Tare R, Andar A, Riehle MO, Herzyk P, et al. The control of human mesenchymal cell differentiation using nanoscale symmetry and disorder. Nat Mater. 2007;6:997-1003.

55. Aviss K, Gough J, Downes S. Aligned electrospun polymer fibres for skeletal muscle regeneration. Eur Cell Mater. 2010;19:193204.

56. Huang NF, Patel S, Thakar RG, Wu J, Hsiao BS, Chu B, et al. Myotube assembly on nanofibrous and micropatterned polymers. Nano Lett. 2006;6:537-42.

57. Reilly GC, Engler AJ. Intrinsic extracellular matrix properties regulate stem cell differentiation. J Biomech. 2010;43:55-62.

58. Discher DE, Janmey P, Wang Y-1. Tissue cells feel and respond to the stiffness of their substrate. Science. 2005;310:1139-43.

59. Levy-Mishali M, Zoldan J, Levenberg S. Effect of scaffold stiffness on myoblast differentiation. Tissue Eng Part A. 2009; 15:93544.

60. Engler AJ, Sen S, Sweeney HL, Discher DE. Matrix elasticity directs stem cell lineage specification. Cell. 2006;126:677-89.

61. Swift J, Ivanovska IL, Buxboim A, Harada T, Dingal PDP, Pinter $\mathrm{J}$, et al. Nuclear lamin-A scales with tissue stiffness and enhances matrix-directed differentiation. Science. 2013;341:1240104.

62. Yang C, Tibbitt MW, Basta L, Anseth KS. Mechanical memory and dosing influence stem cell fate. Nat Mater. 2014;13:645.

63. Jiang T, Carbone EJ, Lo KWH, Laurencin CT. Electrospinning of polymer nanofibers for tissue regeneration. Prog Polym Sci. 2015;46:1-24

64. Nam J, Huang Y, Agarwal S, Lannutti J. Improved cellular infiltration in electrospun fiber via engineered porosity. Tissue Eng. 2007; 13:2249-57.

65. Sundararaghavan HG, Metter RB, Burdick JA. Electrospun fibrous scaffolds with multiscale and photopatterned porosity. Macromol Biosci. 2010;10:265-70.

66. Guex A, Kocher F, Fortunato G, Körner E, Hegemann D, Carrel T, et al. Fine-tuning of substrate architecture and surface chemistry 
promotes muscle tissue development. Acta Biomater. 2012;8: $1481-9$

67. Benoit DS, Schwartz MP, Durney AR, Anseth KS. Small functional groups for controlled differentiation of hydrogelencapsulated human mesenchymal stem cells. Nat Mater. 2008;7:816-23.

68. Zonca MR, Yune PS, Heldt CL, Belfort G, Xie Y. Highthroughput screening of substrate chemistry for embryonic stem cell attachment, expansion, and maintaining pluripotency. Macromol Biosci. 2013;13:177-90.

69. Schindler MS, Chung HY. Nanofibrillar structure and applications including cell and tissue culture. US7704740 B2; 2010.

70. Cushnie EK, Ulery BD, Nelson SJ, Deng M, Sethuraman S, Doty $\mathrm{SB}$, et al. Simple signaling molecules for inductive bone regenerative engineering. PLoS One. 2014;9:e101627.

71. Mei Y, Saha K, Bogatyrev SR, Yang J, Hook AL, Kalcioglu ZI, et al. Combinatorial development of biomaterials for clonal growth of human pluripotent stem cells. Nat Mater. 2010;9:768-78.

72. Yang J, Mei Y, Hook AL, Taylor M, Urquhart AJ, Bogatyrev SR, et al. Polymer surface functionalities that control human embryoid body cell adhesion revealed by high throughput surface characterization of combinatorial material microarrays. Biomaterials. 2010;31:8827-38.

73. Wang D-A, Varghese S, Sharma B, Strehin I, Fermanian S, Gorham J, et al. Multifunctional chondroitin sulphate for cartilage tissue-biomaterial integration. Nat Mater. 2007;6: 385-92.

74. Lo KW-H, Jiang T, Gagnon KA, Nelson C, Laurencin CT. Smallmolecule based musculoskeletal regenerative engineering. Trends Biotechnol. 2014;32:74-81.

75. Lee K, Silva EA, Mooney DJ. Growth factor delivery-based tissue engineering: general approaches and a review of recent developments. J R Soc Interface. 2011;8:153-70.

76. Lieberman JR, Daluiski A, Einhorn TA. The role of growth factors in the repair of bone. J Bone Joint Surg Am. 2002;84:1032-44.

77. Werner S, Grose R. Regulation of wound healing by growth factors and cytokines. Physiol Rev. 2003;83:835-70.

78. Amini AR, Laurencin CT, Nukavarapu SP. Bone tissue engineering: recent advances and challenges. Crit $\operatorname{Rev}^{\mathrm{TM}}$ Biomed Eng. 2012;40:363-408.

79. Lo KWH, Kan HM, Ashe KM, Laurencin CT. The small molecule PKA-specific cyclic AMP analogue as an inducer of osteoblast-like cells differentiation and mineralization. J Tissue Eng Regen Med. 2012;6:40-8.

80. Deng M, Cushnie EK, Lv Q, Laurencin CT. Poly (lactide-coglycolide)-hydroxyapatite composites: the development of osteoinductive scaffolds for bone regenerative engineering. MRS Online Proc Library. 2012;1417. MRS Proceedings, 1417, mrsf11-1417-kk01-01 doi: 10.1557/opl.2012.737.

81. Deng M, Kumbar SG, Lo KWH, Ulery BD, Laurencin CT. Novel polymer-ceramics for bone repair and regeneration. Recent Pat Biomed Eng. 2011;4:168-84.

82. Yasuda M, Ohzeki Y, Shimizu S, Naito S, Ohtsuru A, Yamamoto $\mathrm{T}$, et al. Stimulation of in vitro angiogenesis by hydrogen peroxide and the relation with ETS-1 in endothelial cells. Life Sci. 1998;64:249-58.

83. Milkiewicz M, Hudlicka O, Brown MD, Silgram H. Nitric oxide, VEGF, and VEGFR-2: interactions in activity-induced angiogenesis in rat skeletal muscle. Am J Physiol Heart Circ Physiol. 2005;289:H336-H43.

84. Liu D, Wang Z, Zhan J, Zhang Q, Wang J, Zhang Q, et al. Hydrogen sulfide promotes proliferation and neuronal differentiation of neural stem cells and protects hypoxia-induced decrease in hippocampal neurogenesis. Pharmacol Biochem Behav. 2014;116:55-63.
85. Bhattacharyya S, Nair LS, Singh A, Krogman NR, Greish YE, Brown PW, et al. Electrospinning of poly[bis(ethyl alanato) phosphazene] nanofibers. J Biomed Nanotechnol. 2006;2:36-45.

86. Kumbar SG, James R, Nukavarapu SP, Laurencin CT. Electrospun nanofiber scaffolds: engineering soft tissues. Biomed Mater. 2008;3:034002.

87. Taylor ED, Nair LS, Nukavarapu SP, McLaughlin S, Laurencin CT. Novel nanostructured scaffolds as therapeutic replacement options for rotator cuff disease. J Bone Joint Surg Am. 2010;92: 170.

88. James R, Kumbar S, Laurencin C, Balian G, Chhabra A. Tendon tissue engineering: adipose-derived stem cell and GDF-5 mediated regeneration using electrospun matrix systems. Biomed Mater. 2011;6:025011.

89. James R, Toti US, Laurencin CT, Kumbar SG. Electrospun nanofibrous scaffolds for engineering soft connective tissues. Methods Mol Biol. 2011;726:243-58.

90. Peach MS, James R, Toti US, Deng M, Morozowich NL, Allcock $\mathrm{HR}$, et al. Polyphosphazene functionalized polyester fiber matrices for tendon tissue engineering: in vitro evaluation with human mesenchymal stem cells. Biomed Mater. 2012;7:045016.

91. Peach MS, Kumbar SG, James R, Toti US, Balasubramaniam D, Deng M, et al. Design and optimization of polyphosphazene functionalized fiber matrices for soft tissue regeneration. J Biomed Nanotechnol. 2012;8:107-24.

92. Lu H, Subramony S, Boushell M, Zhang X. Tissue engineering strategies for the regeneration of orthopedic interfaces. Ann Biomed Eng. 2010;38:2142-54.

93. Liu W, Lipner J, Xie J, Manning CN, Thomopoulos S, Xia Y. Nanofiber scaffolds with gradients in mineral content for spatial control of osteogenesis. ACS Appl Mater Interfaces. 2014;6: 2842-9.

94. Li X, Xie J, Lipner J, Yuan X, Thomopoulos S, Xia Y. Nanofiber scaffolds with gradations in mineral content for mimicking the tendon-to-bone insertion site. Nano Lett. 2009;9:2763-8.

95. Ostrovidov S, Shi X, Zhang L, Liang X, Kim SB, Fujie T, et al. Myotube formation on gelatin nanofibers - multi-walled carbon nanotubes hybrid scaffolds. Biomaterials. 2014;35:6268-77.

96. Zhang C, Yuan H, Liu H, Chen X, Lu P, Zhu T, et al. Well-aligned chitosan-based ultrafine fibers committed teno-lineage differentiation of human induced pluripotent stem cells for Achilles tendon regeneration. Biomaterials. 2015;53:716-30.

97. Moffat KL, Kwei AS-P, Spalazzi JP, Doty SB, Levine WN, Lu HH. Novel nanofiber-based scaffold for rotator cuff repair and augmentation. Tissue Eng Part A. 2008;15:115-26.

98. AAOS. The evolving role of bone-graft substitutes. 2010. (http:// www.aatb.org/aatb/files/ccLibraryFiles/Filename/000000000322/ BoneGraftSubstitutes2010.pdf)

99. Khan Y, Yaszemski MJ, Mikos AG, Laurencin CT. Tissue engineering of bone: material and matrix considerations. J Bone Joint Surg Am. 2008;90 Suppl 1:36-42.

100. Sung HJ, Meredith C, Johnson C, Galis ZS. The effect of scaffold degradation rate on three-dimensional cell growth and angiogenesis. Biomaterials. 2004;25:5735-42.

101. Laurencin C, Khan Y, El-Amin SF. Bone graft substitutes. Expert Rev Med Devices. 2005;3:49-57.

102. James R, Deng M, Laurencin CT, Kumbar SG. Nanocomposites and bone regeneration. Front Mater Sci. 2011;5:342-57.

103. Nair LS, Bhattacharyya S, Bender JD, Greish YE, Brown PW, Allcock HR, et al. Fabrication and optimization of methylphenoxy substituted polyphosphazene nanofibers for biomedical applications. Biomacromolecules. 2004;5:2212-20.

104. Shin M, Yoshimoto H, Vacanti JP. In vivo bone tissue engineering using mesenchymal stem cells on a novel electrospun nanofibrous scaffold. Tissue Eng. 2004;10:33-41. 
105. Badami AS, Kreke MR, Thompson MS, Riffle JS, Goldstein AS. Effect of fiber diameter on spreading, proliferation, and differentiation of osteoblastic cells on electrospun poly (lactic acid) substrates. Biomaterials. 2006;27:596-606.

106. Kim H-W, Yu H-S, Lee H-H. Nanofibrous matrices of poly (lactic acid) and gelatin polymeric blends for the improvement of cellular responses. J Biomed Mater Res A. 2008;87:25-32.

107. Shalumon K, Chennazhi K, Tamura H, Kawahara K, Nair S, Jayakumar R. Fabrication of three-dimensional nano, micro and micro/nano scaffolds of porous poly (lactic acid) by electrospinning and comparison of cell infiltration by Z-stacking/three-dimensional projection technique. IET Nanobiotechnol. 2012;6:16-25.

108. Woo KM, Jun J-H, Chen VJ, Seo J, Baek J-H, Ryoo H-M, et al. Nano-fibrous scaffolding promotes osteoblast differentiation and biomineralization. Biomaterials. 2007;28:335-43.

109. Lyu S, Huang C, Yang H, Zhang X. Electrospun fibers as a scaffolding platform for bone tissue repair. J Orthop Res. 2013;31: 1382-9.

110. Yu H-S, Jang J-H, Kim T-I, Lee H-H, Kim H-W. Apatitemineralized polycaprolactone nanofibrous web as a bone tissue regeneration substrate. J Biomed Mater Res A. 2009;88:747-54.

111. Paletta JRJ, Bockelmann S, Walz A, Theisen C, Wendorff JH, Greiner A, et al. RGD-functionalisation of PLLA nanofibers by surface coupling using plasma treatment: influence on stem cell differentiation. J Mater Sci Mater Med. 2010;21:1363-9.

112. Zhou C, Hong Y, Zhang X. Applications of nanostructured calcium phosphate in tissue engineering. Biomater Sci. 2013;1:1012-28.

113. Yuan H, Fernandes H, Habibovic P, de Boer J, Barradas A, de Ruiter A, et al. Osteoinductive ceramics as a synthetic alternative to autologous bone grafting. Proc Natl Acad Sci U S A. 2010;107: 13614-9.

114. Wu Y, Hench LL, Du J, Choy K-L, Guo J. Preparation of hydroxyapatite fibers by electrospinning technique. J Am Ceram Soc. 2004;87:1988-91.

115. Kretlow JD, Mikos AG. Review: mineralization of synthetic polymer scaffolds for bone tissue engineering. Tissue Eng. 2007;13: 927-38.

116. Rezwan K, Chen QZ, Blaker JJ, Boccaccini AR. Biodegradable and bioactive porous polymer/inorganic composite scaffolds for bone tissue engineering. Biomaterials. 2006;27:3413-31.

117. Schneider OD, Weber F, Brunner TJ, Loher S, Ehrbar M, Schmidlin PR, et al. In vivo and in vitro evaluation of flexible, cotton wool-like nanocomposites as bone substitute material for complex defects. Acta Biomater. 2009;5:1775-84.

118. Fujihara K, Kotaki M, Ramakrishna S. Guided bone regeneration membrane made of polycaprolactone/calcium carbonate composite nano-fibers. Biomaterials. 2005;26:4139-47.

119. Tan J, Joo YL. Electrospun calcium phosphate nanofibers. US8512741 B2; 2013.

120. Kim H-W, Kim H-E, Knowles JC. Production and potential of bioactive glass nanofibers as a next-generation biomaterial. Adv Funct Mater. 2006;16:1529-35.

121. Kim H-W, Lee H-H, Knowles JC. Nanofibrous glass tailored with apatite-fibronectin interface for bone cell stimulation. J Nanosci Nanotechnol. 2008;8:3013-9.

122. Sakai S, Yamada Y, Yamaguchi T, Kawakami K. Prospective use of electrospun ultra-fine silicate fibers for bone tissue engineering. Biotechnol J. 2006;1:958-62.

123. Shin S-H, Purevdorj O, Castano O, Planell JA, Kim H-W. A short review: Recent advances in electrospinning for bone tissue regeneration. J Tissue Eng. 2012;3:2041731412443530.

124. Zhang Z, Hu J, Ma PX. Nanofiber-based delivery of bioactive agents and stem cells to bone sites. Adv Drug Deliv Rev. 2012;64:1129-41.
125. Laurencin CT, Ashe KM, Henry N, Kan HM, Lo KW-H. Delivery of small molecules for bone regenerative engineering: preclinical studies and potential clinical applications. Drug Discov Today. 2014;19:794-800.

126. Li C, Vepari C, Jin H-J, Kim HJ, Kaplan DL. Electrospun silkBMP-2 scaffolds for bone tissue engineering. Biomaterials. 2006;27:3115-24.

127. Nie H, Soh BW, Fu Y-C, Wang C-H. Three-dimensional fibrous PLGA/HAp composite scaffold for BMP-2 delivery. Biotechnol Bioeng. 2008;99:223-34.

128. Fu Y-C, Nie H, Ho M-L, Wang C-K, Wang C-H. Optimized bone regeneration based on sustained release from three-dimensional fibrous PLGA/HAp composite scaffolds loaded with BMP-2. Biotechnol Bioeng. 2008;99:996-1006.

129. Liao SS, Cui FZ, Zhang W, Feng QL. Hierarchically biomimetic bone scaffold materials: Nano-HA/collagen/PLA composite. J Biomed Mater Res B Appl Biomater. 2004;69B:158-65.

130. James R, Kesturu G, Balian G, Chhabra AB. Tendon: biology, biomechanics, repair, growth factors, and evolving treatment options. J Hand Surg Am. 2008;33:102-12.

131. Tang JB. Tendon injuries across the world: treatment. Injury. 2006;37:1036-42.

132. Sharma P, Maffulli N. Tendon injury and tendinopathy: healing and repair. J Bone Joint Surg Am. 2005;87:187-202.

133. Liu Y, Ramanath H, Wang D-A. Tendon tissue engineering using scaffold enhancing strategies. Trends Biotechnol. 2008;26:201-9.

134. Kuo CK, Marturano JE, Tuan RS. Novel strategies in tendon and ligament tissue engineering: advanced biomaterials and regeneration motifs. BMC Sports Sci Med Rehabil. 2010;2:20.

135. Zhang X, Bogdanowicz D, Erisken C, Lee NM, Lu HH. Biomimetic scaffold design for functional and integrative tendon repair. J Shoulder Elbow Surg. 2012;21:266-77.

136. Chong AKS, Ang AD, Goh JCH, Hui JHP, Lim AYT, Lee EH, et al. Bone marrow-derived mesenchymal stem cells influence early tendon-healing in a rabbit Achilles tendon model. J Bone Joint Surg Am. 2007;89:74-81.

137. Sahoo S, Ouyang H, Goh JCH, Tay TE, Toh SL. Characterization of a novel polymeric scaffold for potential application in tendon/ ligament tissue engineering. Tissue Eng. 2006;12:91-9.

138. Oryan A, Moshiri A, Sharifi P. Advances in injured tendon engineering with emphasis on the role of collagen implants. Hard Tissue. 2012;1:12

139. Juncosa-Melvin N, Boivin GP, Gooch C, Galloway MT, West JR, Dunn MG, et al. The effect of autologous mesenchymal stem cells on the biomechanics and histology of gel-collagen sponge constructs used for rabbit patellar tendon repair. Tissue Eng. 2006;12: 369-79.

140. Bagnaninchi P-O, Yang Y, El Haj AJ, Maffulli N. Tissue engineering for tendon repair. Br J Sports Med. 2007;41:e10-e.

141. Theisen C, Fuchs-Winkelmann S, Knappstein K, Efe T, Schmitt J, Paletta JR, et al. Influence of nanofibers on growth and gene expression of human tendon derived fibroblast. Biomed Eng Online. 2010;9:9.

142. Funakoshi T, Majima T, Iwasaki N, Suenaga N, Sawaguchi N, Shimode K, et al. Application of tissue engineering techniques for rotator cuff regeneration using a chitosan-based hyaluronan hybrid fiber scaffold. Am J Sports Med. 2005;33:1193-201.

143. Attawia M, Cooper J, Ko F, Laurencin C, Lu H. Ligament and tendon replacement constructs and methods for production and use thereof. US20020133229 A1; 2002.

144. Cooper JJA, Bailey LO, Carter JN, Castiglioni CE, Kofron MD, Ko FK, et al. Evaluation of the anterior cruciate ligament, medial collateral ligament, Achilles tendon and patellar tendon as cell sources for tissue-engineered ligament. Biomaterials. 2006;27: $2747-54$ 
145. Chainani A, Hippensteel KJ, Kishan A, Garrigues NW, Ruch DS, Guilak F, et al. Multilayered electrospun scaffolds for tendon tissue engineering. Tissue Eng Part A. 2013;19:2594-604.

146. Barber JG, Handorf AM, Allee TJ, Li W-J. Braided nanofibrous scaffold for tendon and ligament tissue engineering. Tissue Eng Part A. 2013;19:1265-74.

147. Leung M, Jana S, Tsao C-T, Zhang M. Tenogenic differentiation of human bone marrow stem cells via a combinatory effect of aligned chitosan-poly-caprolactone nanofibers and TGF- $\beta 3$. J Mater Chem B Mater Biol Med. 2013;1:6516-24.

148. Manning C, Schwartz A, Liu W, Xie J, Havlioglu N, SakiyamaElbert S, et al. Controlled delivery of mesenchymal stem cells and growth factors using a nanofiber scaffold for tendon repair. Acta Biomater. 2013;9:6905-14.

149. Hawke TJ, Garry DJ. Myogenic satellite cells: physiology to molecular biology. J Appl Physiol. 2001;91:534-51.

150. Bach A, Beier J, Stern-Staeter J, Horch R. Skeletal muscle tissue engineering. J Cell Mol Med. 2004;8:413-22.

151. Liu W, Wen Y, Bi P, Lai X, Liu XS, Liu X, et al. Hypoxia promotes satellite cell self-renewal and enhances the efficiency of myoblast transplantation. Development. 2012;139:2857-65.

152. Bian W, Bursac N. Engineered skeletal muscle tissue networks with controllable architecture. Biomaterials. 2009;30:1401-12.

153. Gilbert PM, Havenstrite KL, Magnusson KE, Sacco A, Leonardi NA, Kraft P, et al. Substrate elasticity regulates skeletal muscle stem cell self-renewal in culture. Science. 2010;329:1078-81.

154. Cosgrove BD, Gilbert PM, Porpiglia E, Mourkioti F, Lee SP, Corbel SY, et al. Rejuvenation of the muscle stem cell population restores strength to injured aged muscles. Nat Med. 2014;20:255-64.

155. Jun I, Jeong S, Shin H. The stimulation of myoblast differentiation by electrically conductive sub-micron fibers. Biomaterials. 2009;30:2038-47.

156. Choi JS, Lee SJ, Christ GJ, Atala A, Yoo JJ. The influence of electrospun aligned poly(epsilon-caprolactone)/collagen nanofiber meshes on the formation of self-aligned skeletal muscle myotubes. Biomaterials. 2008;29:2899-906.

157. Chain CL, Del Ponte MR, Yue F, Kuang S, Deng M. Design and fabrication of a novel electrospinning system for musculoskeletal tissue regeneration. SURF Symposium. 2014;Paper 95.
158. Del Ponte MR, Chain C, Yue F, Kuang S, Deng M. Biological implications of satellite cells for scaffold-based muscle regenerative engineering. SURF Symposium. 2014;Paper 118.

159. Berendse M, Grounds MD, Lloyd CM. Myoblast structure affects subsequent skeletal myotube morphology and sarcomere assembly. Exp Cell Res. 2003;291:435-50.

160. McKeon-Fischer K, Freeman J. Characterization of electrospun poly (L-lactide) and gold nanoparticle composite scaffolds for skeletal muscle tissue engineering. J Tissue Eng Regen Med. 2011;5:560-8.

161. McKeon-Fischer KD, Rossmeisl JH, Whittington AR, Freeman JW. In Vivo skeletal muscle biocompatibility of composite, coaxial electrospun, and microfibrous scaffolds. Tissue eng part A. 2014.

162. McKeon-Fischer K, Flagg D, Freeman J. Coaxial electrospun poly ( $\varepsilon$-caprolactone), multiwalled carbon nanotubes, and polyacrylic acid/polyvinyl alcohol scaffold for skeletal muscle tissue engineering. J Biomed Mater Res A. 2011;99:493-9.

163. Chen M-C, Sun Y-C, Chen Y-H. Electrically conductive nanofibers with highly oriented structures and their potential application in skeletal muscle tissue engineering. Acta Biomater. 2013;9: $5562-72$.

164. Xu J, Xie Y, Zhang H, Ye Z, Zhang W. Fabrication of PLGA/MWNTs composite electrospun fibrous scaffolds for improved myogenic differentiation of $\mathrm{C} 2 \mathrm{C} 12$ cells. Colloids Surf B Biointerfaces. 2014;123:907-15.

165. Dormer NH, Berkland CJ, Detamore MS. Emerging techniques in stratified designs and continuous gradients for tissue engineering of interfaces. Ann Biomed Eng. 2010;38:2121-41.

166. Seidi A, Ramalingam M, Elloumi-Hannachi I, Ostrovidov S, Khademhosseini A. Gradient biomaterials for soft-to-hard interface tissue engineering. Acta Biomater. 2011;7:1441-51.

167. Yang PJ, Temenoff JS. Engineering orthopedic tissue interfaces. Tissue Eng Part B Rev. 2009;15:127-41.

168. Subramony SD, Dargis BR, Castillo M, Azeloglu EU, Tracey MS, $\mathrm{Su} \mathrm{A}$, et al. The guidance of stem cell differentiation by substrate alignment and mechanical stimulation. Biomaterials. 2013;34: $1942-53$ 